\title{
Carbonic anhydrases and their functional differences in human and mouse sperm physiology
}

\author{
O. José a , P. Torres-Rodríguez a , L.S. Forero-Quintero ${ }^{\mathrm{b}}$, J.C. Chávez a \\ J.L. De la Vega-Beltrán a , F. Carta ${ }^{\text {c }}$, C.T. Supuran ${ }^{\text {c, d }}$, J.W. Deitmer ${ }^{\text {b }}$, C.L. Treviño ${ }^{\text {a, * }}$ \\ a Departamento de Genética del Desarrollo y Fisiología Molecular, Instituto de Biotecnología, Universidad Nacional Autónoma de México, 62210, \\ Cuernavaca, Morelos, Mexico \\ ${ }^{\mathrm{b}}$ Abteilung Allgemeine Zoologie, Fachbereich Biologie, University of Kaiserslautern, D-67653, Kaiserslautern, Germany \\ c Dipartimento di Chimica “U. Schiff”, Laboratorio di Chimica Bioinorganica, Universitá degli Studi di Firenze, Via della Lastruccia 3, Polo Scientifico, 50019, \\ Sesto Fiorentino, Florence, Italy \\ d Dipartimento Neurofarba, Sezione di Scienze Farmaceutiche, Universitá degli Studi di Firenze, Via Ugo Schiff 6, Polo Scientifico, 50019, Sesto Fiorentino, \\ Florence, Italy
}

\section{A R T I C L E I N F O}

Article history:

Received 23 October 2015

Accepted 3 November 2015

Available online $\mathrm{xxx}$

\section{Keywords:}

Sperm

Carbonic anhydrase

Motility

Acrosome reaction

\begin{abstract}
A B S T R A C T
Fertilization is a key reproductive event in which sperm and egg fuse to generate a new individual. Proper regulation of certain parameters (such as intracellular $\mathrm{pH}$ ) is crucial for this process. Carbonic anhydrases (CAs) are among the molecular entities that control intracellular $\mathrm{pH}$ dynamics in most cells. Unfortunately, little is known about the function of CAs in mammalian sperm physiology. For this reason, we re-explored the expression of CAI, II, IV and XIII in human and mouse sperm. We also measured the level of CA activity, determined by mass spectrometry, and found that it is similar in non-capacitated and capacitated mouse sperm. Importantly, we found that CAII activity accounts for half of the total CA activity in capacitated mouse sperm. Using the general CA inhibitor ethoxyzolamide, we studied how CAs participate in fundamental sperm physiological processes such as motility and acrosome reaction in both species. We found that capacitated human sperm depend strongly on CA activity to support normal motility, while capacitated mouse sperm do not. Finally, we found that CA inhibition increases the acrosome reaction in capacitated human sperm, but not in capacitated mouse sperm.
\end{abstract}

(c) 2015 Elsevier Inc. All rights reserved.

\section{Introduction}

Before internal fertilization can occur, spermatozoa travel a long stretch inside the female reproductive tract; throughout their journey in this harsh environment, they face important changes in the concentration of different ions. Sperm encounter reduced $\left[\mathrm{K}^{+}\right]_{\mathrm{e}}$, increased $\left[\mathrm{HCO}_{3}{ }^{-}\right]_{\mathrm{e}}$ (which in turn increases $\left[\mathrm{HCO}_{3}{ }^{-}\right]_{\mathrm{i}}$ ) and $\left[\mathrm{Na}^{+}\right]_{\mathrm{e}}$, and during capacitation the intracellular $\mathrm{Ca}^{2+}$ concentration $\left(\left[\mathrm{Ca}^{2+}\right]_{i}\right)$ increases $[1]$. The increases in $\left[\mathrm{HCO}_{3}{ }^{-}\right]_{\mathrm{i}}$ and $\left[\mathrm{Ca}^{2+}\right]_{i}$ activate soluble adenylate cyclase (SAC). Therefore, SAC is a likely connection between carbonic anhydrases (CAs; metalloenzymes that turn $\mathrm{CO}_{2}$ into $\mathrm{HCO}_{3}{ }^{-}$) and downstream steps in the sperm signaling pathways. It has been demonstrated that cAMP produced by SAC

\footnotetext{
* Corresponding author. Instituto de Biotecnología, Universidad Nacional Autónoma de México, Avenida Universidad 2001, Colonia Chamilpa, Cuernavaca, Morelos C.P. 62210, Mexico.

E-mail address: ctrevino@ibt.unam.mx (C.L. Treviño).
}

has different targets, including protein kinase A (PKA), cyclic nucleotide gated (CNG) channels, sperm $\mathrm{Na}^{+} / \mathrm{H}^{+}$exchanger (sNHE), and exchange protein directly activated by cAMP (EPAC) [2]. In turn, PKA is a crucial modulator of sperm motility through phosphorylation of different proteins. Sperm are immotile inside the epididymis, in part due to the acidic conditions of the extracellular fluid. Upon ejaculation, spermatozoa are mixed with seminal fluid having an alkaline $\mathrm{pH}(7.2-8.4)$ and higher $\left[\mathrm{HCO}_{3}{ }^{-}\right]$. Bicarbonate ions not only help maintain the motility of spermatozoa, but also protect them in the acidic environment of the vagina [3]. These changes constitute the first motility stimulus, and are followed by increases of $\left[\mathrm{HCO}_{3}{ }^{-}\right]$in upper regions of the female tract, which in addition to further activate motility, contribute to the capacitation process. While the role of $\mathrm{HCO}_{3}{ }^{-}$during the acrosome reaction is not as well established, it is now clear that regulation of sperm activity is strongly related to $\left[\mathrm{HCO}_{3}{ }^{-}\right]_{\mathrm{i}}$ levels and $\mathrm{pH}_{\mathrm{i}}$ values. However, the identity and interplay of the molecular entities participating in their modulation remain far from clear. For example, despite the 
importance of CAs in the regulation of $\mathrm{pH}$ in almost every cell type, little is known about their subcellular distribution and their physiological role in mammalian sperm. CAs are present in the three domains of life, though encoded by six evolutionarily unrelated gene families, namely $\alpha, \beta, \gamma, \delta$, $\zeta$ and $\eta$-CAs [4]. The sixteen isoforms of $\alpha$-CAs are the only CAs present in mammals, displaying distinct subcellular and tissue distribution, kinetic properties, and sensitivity to inhibitors [5]. Using different biochemical techniques, it has been shown that isoforms CAI [3], CAII [3,6] and CAXIII [7] are present in human sperm, while isoforms CAII [8], CAIV [9-11] and CAXII [12] are found in mouse sperm. Interestingly, it has been demonstrated that isoform CAIV is transferred to the plasma membrane of non-capacitated mouse sperm as they pass through the epididymis, and that both murine and human non-capacitated sperm respond to increases in extracellular $\mathrm{CO}_{2}$ with an increase in flagellar beat frequency, an effect that can be blocked by the general CA inhibitor ethoxyzolamide (EZA) [11]. Moreover, non-capacitated sperm from CAIV $^{-1-}$ null mice showed a decrease in total CA activity and a reduced response to $\mathrm{CO}_{2}$ compared to the wild type [11]. Another study led to the proposal that glucose consumption and the regulation of flagellar beat frequency in mouse sperm are interconnected through the generation of $\mathrm{HCO}_{3}{ }^{-}$from $\mathrm{CO}_{2}$, a reaction that is mediated by the activity of CAs [13]. Given that various physiological important differences between human and mouse sperm have been established [1,5], and considering the scarcity of studies on CAs in sperm, in this work we set out to compare their distribution and activity between both species using various experimental techniques, along with general and specific CA inhibitors.

\section{Materials and methods}

\subsection{Mouse and human sperm preparation}

Mouse spermatozoa were obtained from adult ( $\sim 3$ months old) male $\mathrm{CD} 1$ or $\mathrm{C} 57 \mathrm{BL} / 6 \mathrm{~J}$ mice. The $\mathrm{CAII}^{-1-}$ mice colony was obtained from the University of Kaiserslautern, Germany. The animals were killed by cervical dislocation and non-capacitated motile spermatozoa were obtained from epididymal caudas in Whitten's medium pH 7.4 using the swim-up technique [14]. Whitten's medium contains (in $\mathrm{mM}$ ): $\mathrm{NaCl} \mathrm{100,} \mathrm{KCl} 4.7, \mathrm{KH}_{2} \mathrm{PO}_{4} 1.2, \mathrm{MgSO}_{4} 1.2$, glucose 5.5, sodium pyruvate 1, Na-L-lactate 4.8, HEPES 20, $\mathrm{NaHCO}_{3} 24$ and $\mathrm{CaCl}_{2} 2$. The use of human sperm in this study was approved by the Bioethics Committee at the Biotechnology Institute, UNAM. Ejaculates were obtained by masturbation from healthy donors after $48 \mathrm{~h}$ of sexual abstinence. Samples that fulfilled the parameters established by the World Health Organization were used. The semen samples were allowed to liquefy at $37{ }^{\circ} \mathrm{C}$ and then the motile spermatozoa were recovered in Ham's F-10 medium pH 7.4 (plus $\mathrm{CaCl}_{2} 2 \mathrm{mM}$ ) using the swim-up technique [15]. To generate capacitated cells, mouse and human sperm samples were incubated in their respective media, supplemented with bovine serum albumin $5 \mathrm{mg} / \mathrm{mL}$. Mouse and human sperm samples (either capacitated or non-capacitated) were then adjusted to a concentration of $10 \times 10^{6}$ cells $/ \mathrm{mL}$, and incubated at $37{ }^{\circ} \mathrm{C}$ with $\mathrm{CO}_{2} 5 \% /$ air $95 \%$ during at least $40 \mathrm{~min}$ or $4 \mathrm{~h}$, respectively. Before each experiment, capacitated human cells were centrifuged during 5 min at $735 \times \mathrm{g}$ and resuspended in physiological solution $\mathrm{pH} 7.4$, which contains (in $\mathrm{mM}$ ): $\mathrm{NaCl} 94, \mathrm{KCl} 4, \mathrm{CaCl}_{2} 2, \mathrm{MgCl}_{2} 1$, sodium pyruvate 1 , $\mathrm{NaHCO}_{3} 25$, glucose 5, HEPES 30 and Na-L-lactate 10 .

\subsection{SDS-PAGE and western blot assays}

After swim-up, mice and human spermatozoa were washed twice with PBS and centrifuged during $5 \mathrm{~min}$ at $735 \times \mathrm{g}$. Pellets were resuspended in $500 \mu \mathrm{L}$ of solubilization buffer and the samples were left in constant agitation during $1.5 \mathrm{~h}$ at $4{ }^{\circ} \mathrm{C}$. Samples were centrifuged at $16,000 \times g$ during $15 \mathrm{~min}$ and proteins in the supernatant were concentrated to $50 \mu \mathrm{L}$ with centrifugal filters Amicon Ultra 10K (Merck Millipore, Carrigtwohill, Ireland). The concentrated protein was mixed with loading buffer as described previously [15]. The sample was then heated at $70{ }^{\circ} \mathrm{C}$ during $10 \mathrm{~min}$ and finally centrifuged at $16,000 \times g$ for $10 \mathrm{~min}$. A volume equivalent to the protein content of $30 \times 10^{6}$ cells was loaded per lane on a $10 \%$ or $15 \%$ SDS-PAGE gel, depending on the condition. Proteins were electrotransferred to an Immobilon P membrane (Millipore, Massachusetts, USA) with a semi-dry electrophoretic transfer cell (Bio-Rad, Mexico City, Mexico) and the membrane was blocked with fat-free milk $5 \% \mathrm{v} / \mathrm{v}$. Membranes were probed with anti-CAII, anti-CAXIII (Sigma Aldrich, Mexico City, Mexico) or anti-CAIV (Santa Cruz Biotechnology, Texas, USA). Immunodetection was performed as described elsewhere [15].

\subsection{Immunocytochemistry}

Mouse and human sperm cells were attached to glass slides and fixed with paraformaldehyde/PBS 4\% during $1 \mathrm{~h}$ at room temperature (RT), and then washed 3 times with PBS. Cells were permeabilized with Triton X-100/PBS $0.1 \%$ for $10 \mathrm{~min}$ and washed 3 times with PBS at room temperature. Non-specific sites were blocked with BSA/PBS 5\% during $2 \mathrm{~h}$ at RT and then incubated overnight at $4{ }^{\circ} \mathrm{C}$ in a $1: 100$ dilution of anti-CAI, anti-CAII or antiCAXIII. Cells were washed 3 times with PBS at RT, incubated with a secondary antibody coupled to Alexa 488 (Invitrogen, Mexico City, Mexico), and washed again 3 times with PBS; finally, the samples were mounted with Citifluor (Electron Microscopy Sciences, Pennsylvania, USA). The fluorescence of cells was observed in a confocal microscope Zeiss LSM510 META with a 100X objective.

\subsection{Determination of CA catalytic activity}

Activity of CAs was determined by measuring the ${ }^{18} \mathrm{O}$ depletion of doubly labeled ${ }^{13} \mathrm{C}^{18} \mathrm{O}_{2}$ through several hydration and dehydration steps of $\mathrm{CO}_{2}$ and $\mathrm{HCO}_{3}{ }^{-}$at RT. The reaction sequence of ${ }^{18} \mathrm{O}$ loss from ${ }^{13} \mathrm{C}^{18} \mathrm{O}^{18} \mathrm{O}(\mathrm{m} / \mathrm{z}=49)$ over the intermediate product ${ }^{13} \mathrm{C}^{18} \mathrm{O}^{16} \mathrm{O}$ $(m / z=47)$ and the end product ${ }^{13} \mathrm{C}^{16} \mathrm{O}^{16} \mathrm{O}(\mathrm{m} / z=45)$ was monitored with a quadrupole mass spectrometer (OmniStar GSD 320; Pfeiffer Vaccum, Asslar, Germany). The relative ${ }^{18} \mathrm{O}$ enrichment was calculated from the measured 45,47 and 49 abundance as a function of time according to the equation: log enrichment $=\log$ $[49 \times 100 /(49+47+45)]$. For the calculation of CA activity in capacitated mouse spermatozoa, the rate of ${ }^{18} \mathrm{O}$ degradation was obtained from the linear slope of the logarithmic enrichment over time, using the analysis software OriginPro 9.1. This rate was compared with that of the non-catalyzed reaction. Enzyme activity in units (U) was calculated from these two values as defined previously [16]. For each experiment the cuvette was filled with $6 \mathrm{~mL}$ of Whitten's medium without $\mathrm{NaHCO}_{3}$ and $5 \times 10^{6}$ (either capacitated or non-capacitated) cells. Measurements were performed either in the absence or presence of CA inhibitors.

\subsection{Motility assays}

Motility of capacitated human and mouse sperm was measured in a Sperm Class Analyzer (SCA Microptic, Barcelona, Spain). Aliquots $\left(10 \times 10^{6}\right.$ cells $\left./ \mathrm{mL}\right)$ were incubated during $30 \mathrm{~min}$ at $37^{\circ} \mathrm{C}$ with $\mathrm{CO}_{2} 5 \% /$ air $95 \%$ either with vehicle (DMSO) or with increasing concentrations of the general CA inhibitor EZA. $10 \mu \mathrm{L}$ of cell sample were placed inside a MicroCell ${ }^{\circledR}$ chamber (mouse) or between a glass slide (human) and a coverslip, and the motility parameters 
VCL (curvilinear velocity), VSL (straight line velocity), VAP (average path velocity), LIN (linearity), STR (straightness), WOB (wobble), ALH (amplitude of lateral head displacement) and BCF (beat cross frequency) of at least 200 cells per experiment were calculated by the SCA motility software from a stack of images acquired at $50 \mathrm{~Hz}$ and with a $10 \mathrm{X}$ objective. Analyses of numerical data for trajectories were done with the software SigmaPlot 10 (California, USA).

\subsection{Acrosome reaction assays}

Acrosome reaction (AR) was promoted in capacitated human and mouse sperm by incubation at $37{ }^{\circ} \mathrm{C}$ with $\mathrm{CO}_{2} 5 \%$ /air $95 \%$ for 30 min with physiological inductors of the AR, namely progesterone $(10 \mu \mathrm{M})$ for human or zona pellucida (ZP; $5 \mathrm{ZP}$ equivalents $/ \mu \mathrm{L})$ for mouse, with or without 15 min pre-incubation in the presence of the general CA inhibitor, EZA $30 \mu \mathrm{M}$. Sperm were also incubated with either a $\mathrm{Ca}^{2+}$ ionophore ionomycin $10 \mu \mathrm{M}$ or without any inductor of $\mathrm{AR}$, as positive and negative controls, respectively. Human and mouse sperm were fixed, stained with FITC-PSA $(25 \mu \mathrm{g} /$ $\mathrm{mL}$, PBS pH 7.4) or Coomassie Blue G-250 0.22\% v/v, respectively, and AR was evaluated as previously described $[17,18]$.

\subsection{Statistical analyses}

All statistical analyses were performed with the freeware KyPlot 2.0 (Tokyo, Japan), and statistical values are shown as mean \pm standard error of the mean (S.E.M.). Student's $t$ tests were used for calculation of significant differences and are represented in the figures and the table as: ${ }^{*} P \leq 0.05,{ }^{* *} P \leq 0.01$ and ${ }^{* * *} P \leq 0.001$.

\section{Results and discussion}

\subsection{Human and mouse sperm express different CA isoforms}

The physiological importance of CAs has been clearly demonstrated in several types of cells [19]; however, little is known about their presence in mammalian sperm and even less is known about their participation in sperm physiology [5]. Some $\alpha$-CA isoforms have been detected in mammalian sperm (human and mouse) through very different experimental techniques $[3,6-9,11,12]$; for this reason, in this study we re-explored in a more systematic and uniform approach the presence of the isoforms CAI (cytosolic), CAII (cytosolic), CAIV (GPI-anchored) and CAXIII (cytosolic) in human and mouse sperm through western blot and immunocytochemistry assays. Western blot experiments allowed us to confirm the presence of CAII and to detect for the first time CAXIII in human sperm (Fig. 1A,C), while CAIV, which had not been explored before in these cells, was not found (Fig. 1B). On the other hand CAII, CAIV, and also for the first time CAXIII, were detected in mouse sperm (Fig. 1D-F). CAI was also assayed in both species, but no band with the appropriate molecular weight was detected. On the other hand, our immunocytochemistry assays revealed that CAI, CAII and CAXIII localized to the flagellum of human sperm (Fig. 1G-I). While these three antibodies were also tested in mouse sperm samples (Fig. 1J-L), only CAII was found in this species, both in the flagellum and in the acrosomal region (Fig. $1 \mathrm{~K}$ ).

\subsection{Capacitated mouse sperm possess CA activity}

A previous study demonstrated that CAs are active in noncapacitated mouse sperm [11]. Given that there are important physiological differences between non-capacitated and capacitated spermatozoa [1], we decided to explore whether CAs are also active in capacitated cells, and if so, whether there is any difference in the total activity of CAs between the two physiological states. Fig. 2A shows for the first time that CAs are also active in capacitated mouse sperm, and that the magnitude of CA activity is similar to that of non-capacitated cells. Considering that only capacitated cells have the ability to fertilize [1], we decided to use only capacitated mouse cells in all further experiments. As a first approach, ethoxyzolamide (EZA), a general inhibitor of CAs, was used at various concentrations, aiming to inhibit CA activity in capacitated mouse cells. As seen in Fig. 2B, EZA significantly diminished CA activity in a dose-dependent manner. In these trials we also tested six different recently designed permeable and impermeable CA inhibitors $[19,20]$ whose expected specific targets are CAVII, CAIX and CAXII. The inhibitory constants of these compounds were determined only for the human CA isoforms [19,20]. In our experiments, the concentrations needed to obtain a significant inhibition of CA activity were above $100 \mu \mathrm{M}$ in all cases (data not shown), which makes EZA the most potent CA inhibitor in our model among the ones tested. Considering that CAII was the only isoform we detected by both western blot and immunocytochemistry in mouse sperm, and given the availability of $\mathrm{CAII}^{-1-}$ null mice, we also explored the contribution of CAII to the total CA activity in these cells (Fig. 2C). We found that total CA activity decreases by $50 \%$ in $\mathrm{CAII}^{-1}{ }^{-}$compared to WT cells, which means that CAII contributes to half of the total activity in capacitated mouse cells; and thus other isoforms, such as CAIV [11], are responsible for the remaining activity. Human CA activity could not be measured due to restrictions on the use of human sperm at the University of Kaiserslautern.

\subsection{Human sperm motility strongly depends on CA activity}

Motility is modulated by different factors including $\mathrm{pH}_{\mathrm{i}}$ [5]. It was previously demonstrated that general $C A$ inhibitors such as EZA and acetazolamide decrease beat cross frequency (BCF) in a dose-dependent manner in non-capacitated mouse sperm [11]. In this work we explored the possible participation of CAs in capacitated human and mouse sperm motility analyzing seven different parameters, in addition to BCF. All eight parameters were affected by EZA in a dose-dependent manner in capacitated human cells, and the observed changes were statistically significant starting at EZA $10 \mathrm{nM}$ (Fig. $3 \mathrm{~A}-\mathrm{H}$ ). Interestingly, and in contrast to results reported for non-capacitated mouse sperm, among the eight motility parameters analyzed in capacitated mouse sperm, five of them decreased significantly only at EZA $100 \mu \mathrm{M}$ (Table 1).

Altogether, these data demonstrate that CAs play a preponderant role in the regulation of capacitated human sperm motility; and although we demonstrated that CAs are active in capacitated mouse sperm, they do not seem to play a major role in the regulation of motility (at least under our experimental conditions). These results in capacitated mouse sperm were surprising, considering that inhibition of CAs in non-capacitated cells had been previously reported to alter at least BCF [11]. The difference in the results obtained for mouse sperm might very well be caused by the different physiological state of cells (non-capacitated versus capacitated), but it could also be due to the differences in the composition of media (the concentration of pyruvate is five times higher in the medium used in this work).

\subsection{CA inhibition potentiates acrosome reaction in capacitated human sperm}

We explored the possible participation of CAs in both species during the AR in response to physiological inductors. As shown in Fig. $4 \mathrm{~A}$, progesterone $10 \mu \mathrm{M}$ promotes the AR in capacitated human sperm, albeit small, at a level consistent with previous reports [21], and pre-incubation of 15 min with EZA $30 \mu \mathrm{M}$ causes a two-fold potentiation effect in the AR. Regarding these results, 
A)

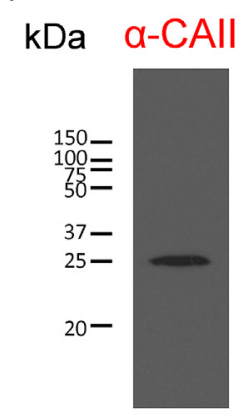

B)

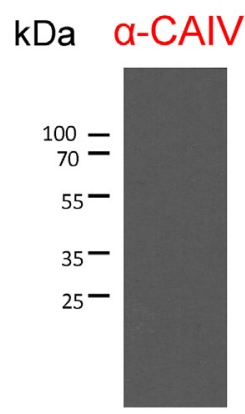

G)

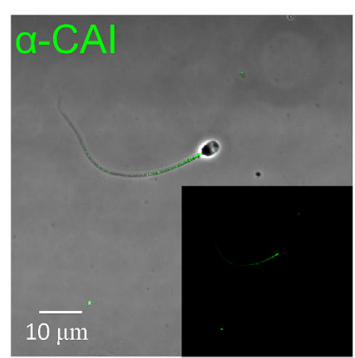

J)

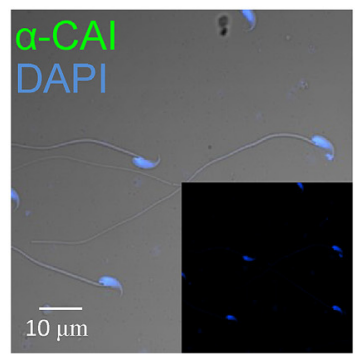

C)

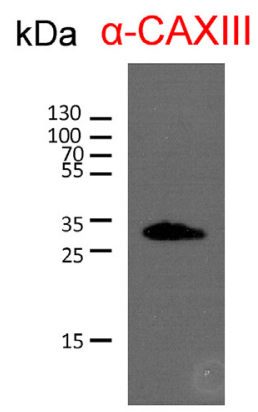

D)

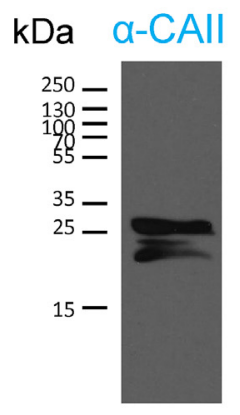

E)

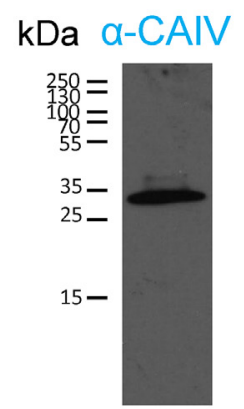

F)

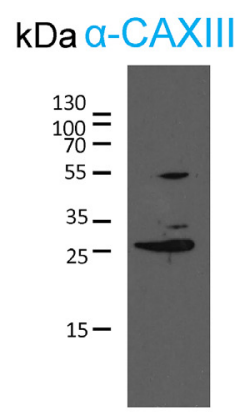

H)

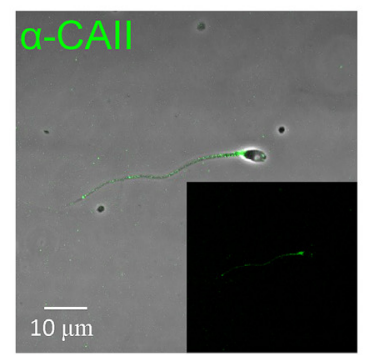

K)

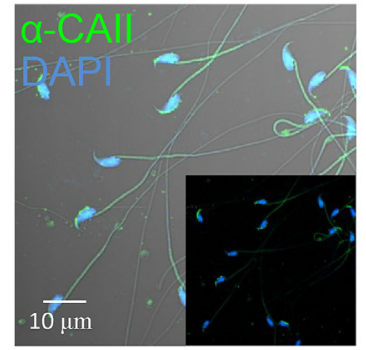

I)

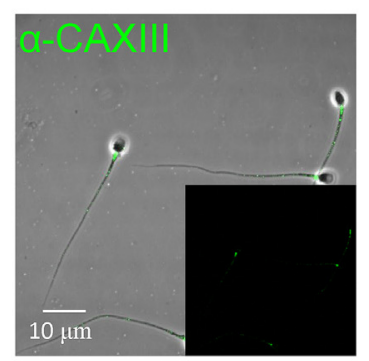

L)

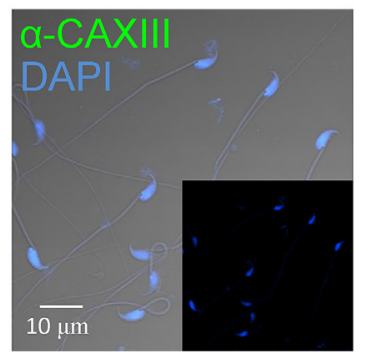

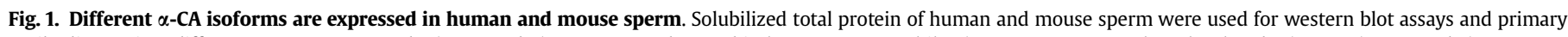

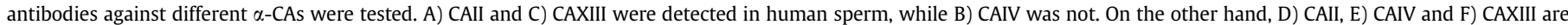

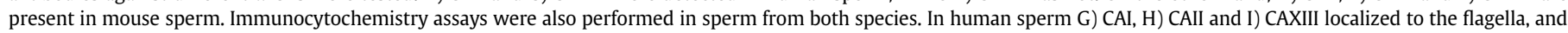

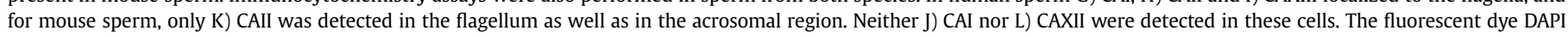
stains the nuclei (blue) in mouse sperm only. Images are representative of at least 3 experiments.

progesterone is known to activate CatSper directly in human sperm $[22,23]$ and promote hyperactivated motility, but so far it is unknown whether this activation of CatSper is somehow related to the AR. Presumably, CA inhibition increases the $\mathrm{pH}_{\mathrm{i}}$ enough to activate CatSper, and this in turn allows enough $\mathrm{Ca}^{2+}$ to enter the cells, inducing the AR. On the other hand, previous exposure of capacitated mouse cells to EZA $30 \mu \mathrm{M}$ did not change the level of the AR induced by zona pellucida (Fig. 4B). Although we detected
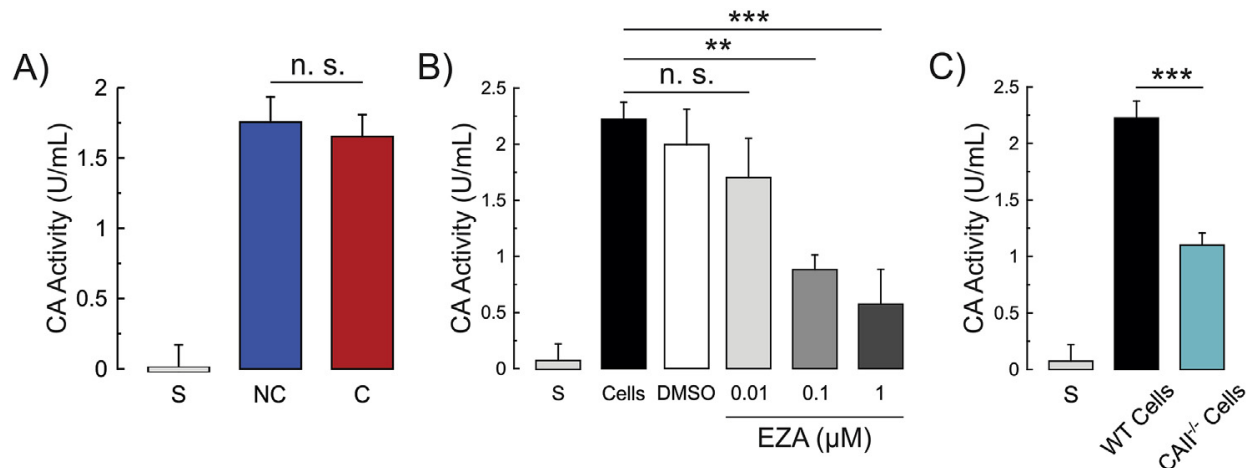

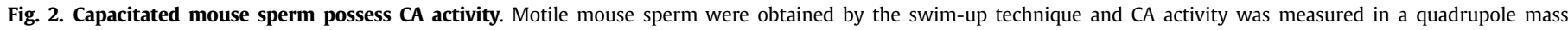

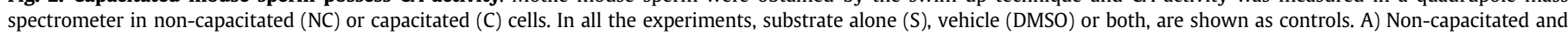

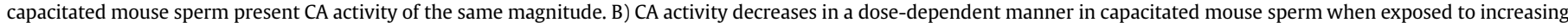

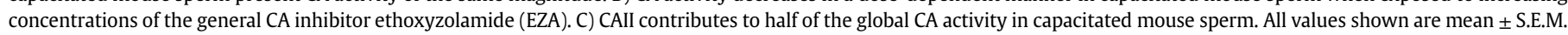
of at least 3 experiments. 
A)

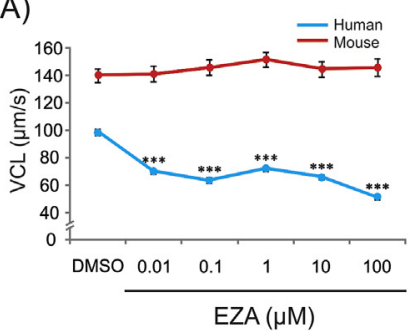

E)

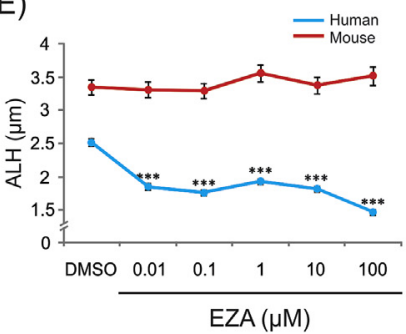

B)

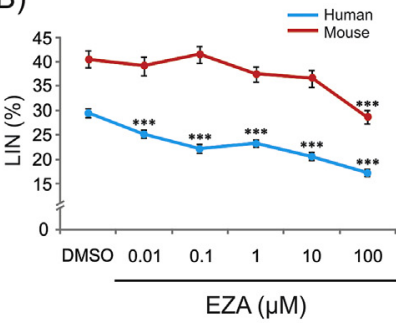

F)

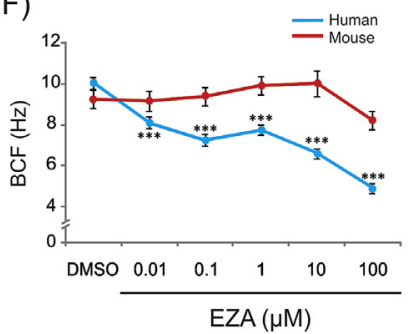

C)

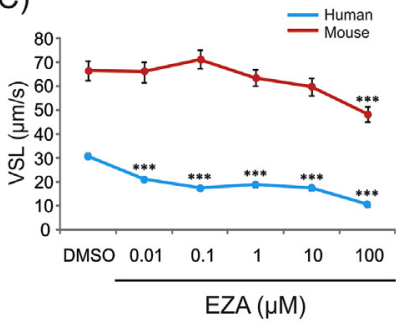

G)

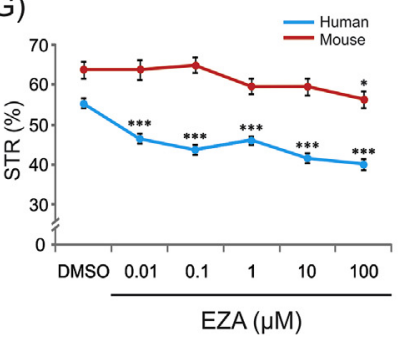

D)

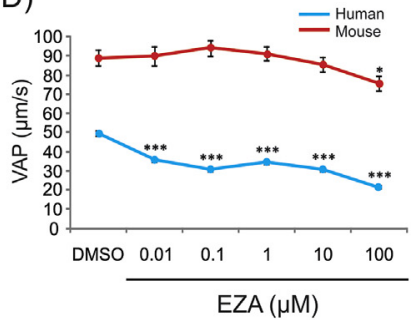

H)

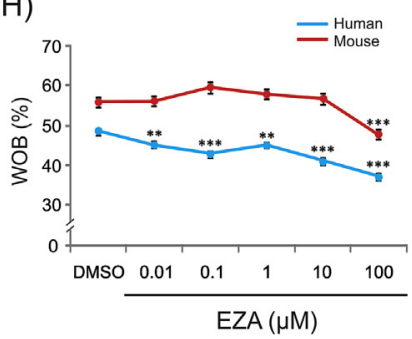

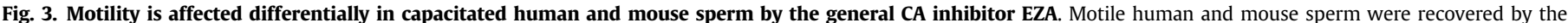

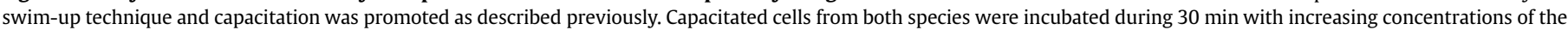

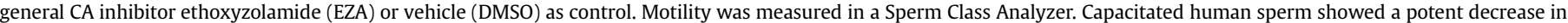

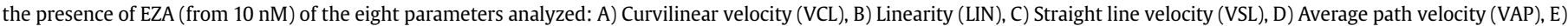

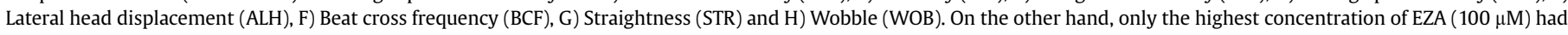
an inhibitory effect in five of the parameters measured in capacitated mouse sperm (Fig. 3B-D, $\mathrm{G}$ and $\mathrm{H}$ ). All values shown are mean $\pm \mathrm{S}$. E. M of at least 3 experiments.

Table 1

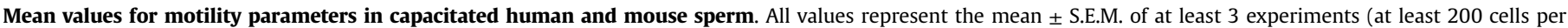

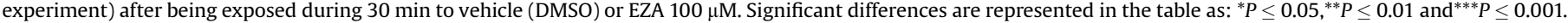

\begin{tabular}{|c|c|c|c|c|}
\hline \multirow[t]{2}{*}{ Motility parameter } & \multicolumn{2}{|c|}{ Capacitated human sperm } & \multicolumn{2}{|c|}{ Capacitated mouse sperm } \\
\hline & DMSO & EZA $100 \mu \mathrm{M}$ & DMSO & EZA $100 \mu \mathrm{M}$ \\
\hline VCL & $98.65 \pm 2.34 \mu \mathrm{m} / \mathrm{s}$ & $50.78 \pm 1.58 \mu \mathrm{m} / \mathrm{s}^{* * *}$ & $140.19 \pm 4.96 \mu \mathrm{m} / \mathrm{s}$ & $145.85 \pm 6.30 \mu \mathrm{m} / \mathrm{s}$ \\
\hline VSL & $30.84 \pm 1.03 \mu \mathrm{m} / \mathrm{s}$ & $10.55 \pm 0.61 \mu \mathrm{m} / \mathrm{s}^{* * *}$ & $66.63 \pm 3.98 \mu \mathrm{m} / \mathrm{s}$ & $48.61 \pm 3.25 \mu \mathrm{m} / \mathrm{s}^{* * *}$ \\
\hline VAP & $49.67 \pm 1.24 \mu \mathrm{m} / \mathrm{s}$ & $21.69 \pm 0.84 \mu \mathrm{m} / \mathrm{s}^{* * *}$ & $88.85 \pm 4.11 \mu \mathrm{m} / \mathrm{s}$ & $75.81 \pm 3.77 \mu \mathrm{m} / \mathrm{s}^{*}$ \\
\hline LIN & $29.51 \pm 0.84 \%$ & $17.24 \pm 0.75 \% * * *$ & $40.53 \pm 1.78 \%$ & $28.65 \pm 1.39 \%^{* * *}$ \\
\hline STR & $55.40 \pm 1.15 \%$ & $40.09 \pm 1.31 \% * * *$ & $63.78 \pm 2.14 \%$ & $56.33 \pm 2.06 \% *$ \\
\hline WOB & $48.46 \pm 0.76 \%$ & $37.21 \pm 0.92 \% * * *$ & $55.90 \pm 1.13 \%$ & $47.43 \pm 1.30 \% * * *$ \\
\hline ALH & $2.52 \pm 0.05 \mu \mathrm{m}$ & $1.46 \pm 0.04 \mu \mathrm{m}^{* * *}$ & $3.35 \pm 0.11 \mu \mathrm{m}$ & $3.52 \pm 0.14 \mu \mathrm{m}$ \\
\hline $\mathrm{BCF}$ & $10.03 \pm 0.27 \mathrm{~Hz}$ & $4.90 \pm 0.23 \mathrm{~Hz}^{* * *}$ & $9.25 \pm 0.43 \mathrm{~Hz}$ & $8.23 \pm 0.44 \mathrm{~Hz}$ \\
\hline
\end{tabular}

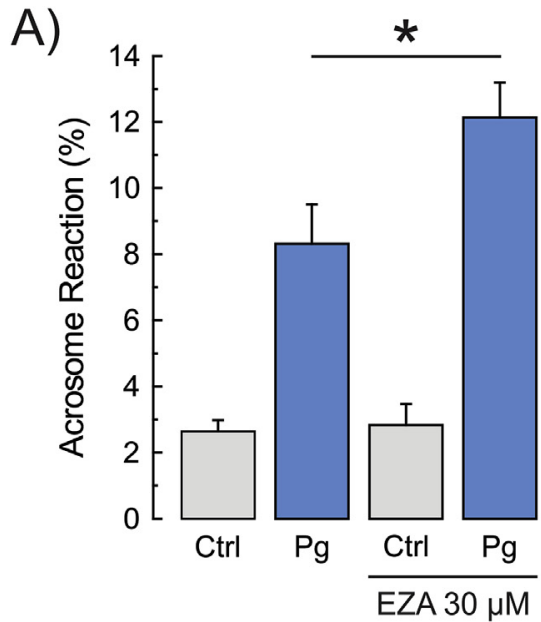

B)

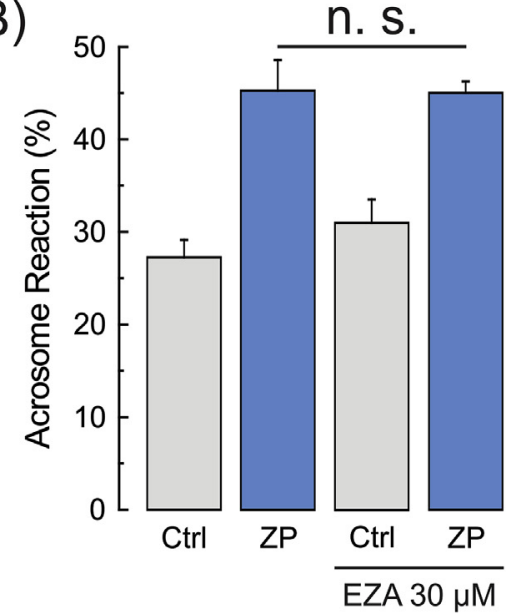

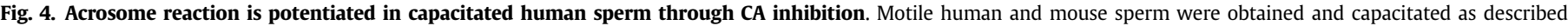

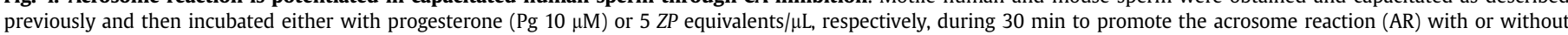

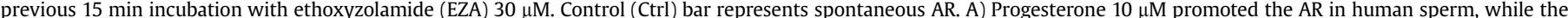

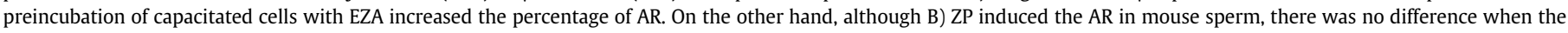
cells were pre-incubated with EZA. All values shown are mean \pm S.E.M. of at least 3 experiments. 
CAII by immunocytochemistry at the acrosomal region of mouse sperm, these results rule out the possible participation of this isoform in the AR induced by ZP. Taken together, these results suggest that the AR signaling pathways are different in human and mouse sperm, although the differences may also be attributable to the different molecules used to induce the AR (a hormone versus proteins).

It is also important to mention that CAs can form either physical or functional metabolons with many different anion exchangers, which makes the effect of these enzymes in mammalian sperm physiology even more complex. Although mouse sperm are often used as an experimental model, and the information thus gathered is often extrapolated to human sperm physiology, our results highlight the importance of using both species as experimental models. Indeed, differences between the two species such as the ones we found in this work have also been recently reported elsewhere. Among them, the differential function of certain ion channels and transporters must be mentioned [1,5]. Finally, knowing that CAs play an important role in mammalian sperm physiology, further studies must be done to investigate the presence of others isoforms in sperm, to continue testing specific inhibitors for the different isoforms, and when possible, to elucidate their particular roles in sperm physiology with the use of KO mice.

\section{Acknowledgments}

We thank Xochitl Alvarado Affantranger, Holger M. Becker, Hans-Peter Schneider, Elizabeth Mata and Graciela Cabeza for their excellent technical assistance. Special thanks to Marcela B. Treviño for critically reviewing the final manuscript. This work was supported by the Alexander von Humboldt Foundation (Research Linkage Programme to CT), CONACyT-Mexico 128566 to CT and DGAPA/UNAM (IN202212-3 to CT).

\section{Transparency document}

Transparency document related to this article can be found online at http://dx.doi.org/10.1016/j.bbrc.2015.11.021.

\section{References}

[1] A. Darszon, T. Nishigaki, C. Beltran, C.L. Trevino, Calcium channels in the development, maturation, and function of spermatozoa, Physiol. Rev. 91 (2011) 1305-1355, http://dx.doi.org/10.1152/physrev.00028.2010.

[2] M.G. Buffone, E.V. Wertheimer, P.E. Visconti, D. Krapf, Central role of soluble adenylyl cyclase and cAMP in sperm physiology, Biochim. Biophys. Acta Mol. Basis Dis. 1842 (2014) 2610-2620, http://dx.doi.org/10.1016/ j.bbadis.2014.07.013.

[3] S. Ali Akbar, K.H. Nicolaides, P.R. Brown, Carbonic anhydrase isoenzymes CAI and CAII in semen, decidua, chorionic villi and various fetal tissues, Early Hum. Dev. 51 (1998) 205-211. http://www.ncbi.nlm.nih.gov/pubmed/9692790.

[4] S. Del Prete, D. Vullo, G.M. Fisher, KT. Andrews, S.-A. Poulsen, C. Capasso, et al. Discovery of a new family of carbonic anhydrases in the malaria pathogen Plasmodium falciparum-The $\eta$-carbonic anhydrases, Bioorg. Med. Chem. Lett. 24 (2014) 4389-4396, http://dx.doi.org/10.1016/j.bmcl.2014.08.015.
[5] T. Nishigaki, O. José, A.L. González-Cota, F. Romero, C.L. Treviño, A. Darszon Biochemical and Biophysical Research Communications, Intracellular pH in sperm physiology, Biochem. Biophys. Res. Commun. 450 (2014) 1149-1158, http://dx.doi.org/10.1016/j.bbrc.2014.05.100.

[6] S. Parkkila, K. Kaunisto, S. Kellokumpu, H. Rajaniemi, A high activity carbonic anhydrase isoenzyme (CA II) is present in mammalian spermatozoa, Histochemistry 95 (1991) 477-482. http://www.ncbi.nlm.nih.gov/pubmed/ 1907954.

[7] J. Lehtonen, B. Shen, M. Vihinen, A. Casini, A. Scozzafava, C.T. Supuran, et al., Characterization of CA XIII, a novel member of the carbonic anhydrase isozyme family, J. Biol. Chem. 279 (2004) 2719-2727, http://dx.doi.org/ 10.1074/jbc.M308984200.

[8] P. Mezquita, C. Mezquita, J. Mezquita, Novel transcripts of carbonic anhydrase II in mouse and human testis, Mol. Hum. Reprod. 5 (1999) 199-205.

[9] E. Ekstedt, L. Holm, Y. Ridderstråle, Carbonic anhydrase in mouse testis and epididymis; transfer of isozyme IV to spermatozoa during passage, 2004, pp. $167-173$.

[10] S.B. Sleight, P.V. Miranda, N.-W. Plaskett, B. Maier, J. Lysiak, H. Scrable, et al., Isolation and proteomic analysis of mouse sperm detergent-resistant membrane fractions: evidence for dissociation of lipid rafts during capacitation, Biol. Reprod. 73 (2005) 721-729, http://dx.doi.org/10.1095/ biolreprod.105.041533.

11] P.M. Wandernoth, M. Raubuch, N. Mannowetz, H.M. Becker, J.W. Deitmer, W.S. Sly, et al., Role of carbonic anhydrase IV in the bicarbonate-mediated activation of murine and human sperm, PLoS One 5 (2010) e15061, http:// dx.doi.org/10.1371/journal.pone.0015061.

[12] P. Halmi, J. Lehtonen, A. Waheed, W.S. Sly, S. Parkkila, Expression of hypoxiainducible, membrane-bound carbonic anhydrase isozyme XII in mouse tissues, Anat. Rec. A. Discov. Mol. Cell. Evol. Biol. 277 (2004) 171-177, http:// dx.doi.org/10.1002/ar.a.20001.

[13] N. Mannowetz, P.M. Wandernoth, G. Wennemuth, Glucose is a pH-dependent motor for sperm beat frequency during early activation, PLoS One 7 (2012) e41030, http://dx.doi.org/10.1371/journal.pone.0041030.

[14] F.A. Navarrete, F.A. García-Vázquez, A. Alvau, J. Escoffier, D. Krapf, C. SánchezCárdenas, et al., Biphasic role of calcium in mouse sperm capacitation signaling pathways, J. Cell. Physiol. (2015), http://dx.doi.org/10.1002/ jсp. $24873 \mathrm{n} / \mathrm{a}-\mathrm{n} / \mathrm{a}$.

[15] I. López-González, P. Torres-Rodríguez, O. Sánchez-Carranza, A. Solís-López, C.M. Santi, A. Darszon, et al., Membrane hyperpolarization during human sperm capacitation, Mol. Hum. Reprod. 20 (2014) 619-629, http://dx.doi.org/ 10.1093/molehr/gau029.

[16] M.R. Badger, G.D. Price, Carbonic anhydrase activity associated with the cyanobacterium Synechococcus PCC7942, Plant Physiol. 89 (1989) 51-60 http://dx.doi.org/10.1104/pp.89.1.51.

[17] N.L. Cross, S. Meizel, Methods for evaluating the acrosomal status of mammalian sperm, Biol. Reprod. 41 (1989) 635-641, http://dx.doi.org/ 10.1095/biolreprod41.4.635.

[18] J.L. De La Vega-Beltran, C. Sánchez-Cárdenas, D. Krapf, E.O. HernandezGonzález, E. Wertheimer, C.L. Treviño, et al., Mouse sperm membrane potential hyperpolarization is necessary and sufficient to prepare sperm for the acrosome reaction, J. Biol. Chem. 287 (2012) 44384-44393, http://dx.doi.org/ 10.1074/jbc.M112.393488.

[19] C.T. Supuran, Carbonic anhydrases: novel therapeutic applications for inhibitors and activators, Nat. Rev. Drug Discov. 7 (2008) 168-181, http:// dx.doi.org/10.1038/nrd2467.

[20] M. Bozdag, M. Pinard, F. Carta, E. Masini, A. Scozzafava, R. Mckenna, et al, Class of 4-sulfamoylphenyl- $\omega$-aminoalkyl ethers with effective carbonic anhydrase inhibitory action and antiglaucoma effects, 2014.

[21] A. Calogero, $\gamma$-Aminobutyric acid (GABA) A and B receptors mediate the stimulatory effects of GABA on the human sperm acrosome reaction: interaction with progesterone, Fertil. Steril. 71 (1999) 930-936, http://dx.doi.org/ 10.1016/S0015-0282(99)00063-1.

[22] P.V. Lishko, I.L. Botchkina, Y. Kirichok, Progesterone activates the principa $\mathrm{Ca}^{2+}$ channel of human sperm, Nature 471 (2011) 387-391, http://dx.doi.org 10.1038/nature09767.

[23] T. Strünker, N. Goodwin, C. Brenker, N.D. Kashikar, I. Weyand, R. Seifert, et al. The CatSper channel mediates progesterone-induced $\mathrm{Ca}^{2+}$ influx in human sperm, Nature 471 (2011) 382-386, http://dx.doi.org/10.1038/nature09769. 